\title{
On the Relationship between Writing Proficiency and Instrumental/Integrative Motivation among Iranian IELTS Candidates
}

\author{
Ismaeil Fazel \\ Vancouver Georgia College, Canada \\ Email: ar.ahmadi@yahoo.com
}

Alireza Ahmadi

Shiraz University, Iran

\begin{abstract}
The present study aimed at making a comparison between integratively motivated IELTS candidates and their instrumentally motivated peers in terms of their proficiency. Moreover, the cohorts were compared based on their proficiency scores on IELTS Test. The participants were initially 245 Iranian IELTS candidates who had taken the actual IELTS test in Iran; in addition to that, a questionnaire by Laine (1987) was utilized to determine the type of motivation each participant possessed. The data made up two groups of 86 integrative and 110 instrumental candidates. Using the results obtained from the proficiency test, a one-way ANOVA was run. The results indicated there was no statistically significant difference between the two groups with regard to their proficiency. It therefore was concluded that the two cohorts stood at the same level of proficiency. Moreover, the statistical analyses, using one-way ANOVA, revealed there was no significant difference between the integratively oriented participants and instrumentally oriented ones as far as their writing performance exam was concerned.
\end{abstract}

Index Terms -instrumental, integrative, motivation, writing, IELTS

\section{INTRODUCTION}

Needless to say, motivation plays a pivotal role in life. According to Brown (1987, p.114) motivation is "an inner drive, impulse, emotion or desire that moves one to a particular action".

In education, given the difficulties associated with learning and the required persistence in the process, motivation takes on a significant role. According to Chomsky (1988, p.181) "about 99 percent of teaching is making the students feel interested in the material".

When it comes to language learning, motivation takes on a more crucial role. As regards the central part motivation plays in learning, Oxford and Shearin (1994) claim that motivation influences the amount of input learners receive in the target language, the amount of L2 learning strategies they utilize, the extent they interact with native speakers and the extent they maintain L2 skills after language study is over.

\section{A. Types of Motivation}

As for the classification of motivation, different kinds of motivation have been proposed. Deci and Ryan (1985) differentiate between intrinsic or extrinsic motivation. Intrinsic motivation is generally possessed by people having personal interest(s) in doing something. Extrinsic motivation, on the other hand, derives from an anticipation of rewards such as praise, awards, prizes, and evaluation, and fear for punishment. An extrinsically motivated student does the activity in order to obtain some reward or avoid some punishment external to the activity itself and this kind of motivation refers to learning situations where the reason for doing a task is something other than an interest in the task itself and undertaking the task may be something the person feels pressured to do rather than genuinely wants to do.

Gardner and Lambert (1972) differentiate between two kinds of motivation: instrumental and integrative. Integrative orientation occurs once a learner tries to identify himself with the culture of L2 group; it characterizes students who study a second language because they are interested in the cultural values of the target language group. An instrumental motive occurs when a learner wishes to attain a goal by means of L2 and refers to language situations where the student has a utilitarian goal for instance employment, professional advancement, or exam purposes. Gardner and Lambert (1972) suggest that integrative motivation is more effective for second language acquisition. It is believed that students who like the people that speak the language, admire the culture and have a desire to become familiar with or even integrate into the society in which the language is used are most successful (Falk, 1978). In contrast to integrative motivation, there is instrumental motivation. Hudson (2000) characterizes instrumental motivation by the desire to obtain something practical or concrete from the study of a second language. Brown (2007) makes the point that both 
integrative and instrumental motivations are not necessarily mutually exclusive. Learners rarely select one form of motivation when learning a second language, but rather a combination of both.

Irrespective of the types identified for motivation, obviously motivation is an important factor in L2 achievement.

Globally, language learners attempt to attain certain goals, one of the most significant of which is writing achievement. Throughout the history of education, language researchers have been at pains to find effective ways to help students achieve writing as a major skill. It goes without saying that motivation has a leading role in gaining writing proficiency. The point at issue is what type of motivation can be more conducive to writing achievement.

\section{B. Significance of L2 Writing}

Writing is a mode of learning, a facility which gives students the power to create meaning and to affect those with whom they share their writing. Writing, then, is far more than merely the act of transferring thought to paper; the act of writing helps to shape and refine our thinking. It seems, however, that teaching and learning this skill can be the most demanding task for both teachers and students. This means that writing requires a good command of language knowledge as well as the orchestration of several processes. Therefore, it may be reasonable to survey different views concerning this skill as well as the different studies conducted on $\mathrm{L}_{2}$ writing.

Academic writing ability has been particularly recognized as one of the most crucial aspects of language ability for successful academic achievement. Although many researches have been conducted concerning this ability, no study thus far has examined the motivational factors on students $\mathrm{L}_{2}$ writing development. The present study aimed to investigate the role motivation played with its sub-types, instrumental and integrative, in writing proficiency among IELTS students in Chabehar, Iran.

\section{The Current Status of IELTS}

The International English Language Testing System (IELTS) is widely recognized as a reliable means of assessing whether candidates are ready to study or train in the medium of English.

All IELTS candidates take the same listening and speaking modules. There is a choice of reading and writing modules according to whether a candidate is taking the academic or general training version of the test. The academic version of the reading and the writing modules is especially designed for candidates taking the test for entry to undergraduate or postgraduate studies or for professional reasons. The general training version of these modules, on the other hand, has been designed for candidates taking the test for entering to vocational or training programs not at degree level, for admission to secondary school, and for immigration purpose.

IELTS results are reported on a nine-band scale. In addition to the score for overall language ability, IELTS provides a score, in the form of a profile, for each of the four skills. These scores are also reported on a nine-band scale. Each Overall Band Score (OBS) corresponds to a descriptive statement which gives a summary of the English language ability of a candidate classified at that level.

\section{The Academic Writing Module}

The Academic Writing Module takes 60 minutes; there are two tasks to complete. It is suggested that about 20 minutes be spent on task 1 which requires candidates to write at least 150 words. Task 2 requires at least 250 words and should take about 40 minutes. The assessment of task 2 carries more weight in marking than task 1 . In task 1 , candidates are asked to look at a diagram or table and to present the information in their own words. They are assessed on their ability to organize, present, and possibly compare data, describe the stages of a process, describe an object or event, or explain how something works. In task 2, candidates are presented with a point of view, argument or problem. They are assessed on their ability to present a solution to the problem, present and justify an opinion, compare and contrast evidence and opinions, evaluate and challenge ideas, evidence or arguments. Candidates are also judged on their ability to write in an appropriate style.

\section{LITERATURE REVIEW}

Gardner and his associates (Gardner and Lambert, 1959 \& 1972; Gardner, 1968, 1979 \& 1985) draw a distinction between integrative and instrumental orientation to second language learning. The former means that the learner wishes to identify him/herself as part of the community where the target language is spoken. The latter occurs when the learner finds the utilitarian value in learning a language, such as a future career perspective.

Gardner and Lambert (1972) carried out empirical studies in different contexts showing the effect of two different types of integrative and instrumental motivation on $\mathrm{L}_{2}$ learning. Students with integrative orientation were found to be more successful as compared with those with instrumental motivation.

Nevertheless, contrary to their expectations, Lukmani (1972) found that the two kinds of motivation were related to each other as well as ESL achievement. He reported that instrumental motivation was more highly correlated with achievement in English than integrative orientation.

Quite a few studies have been done after Gardner and Lambert's controversial researches and results; some have challenged their model and some have attempted to supplement their theories. Oller, Baca and Vigil (1977) carried out a study on Mexican-Americans in the state of New Mexico and reached the conclusion that the students who were anti- 
integrative towards the Anglo-American majority but were instrumentally motivated did better on the proficiency test. One year later, Oller and Perkins (1978) conducted a study on a group of Chinese alumni in America and concluded that positive attitudes towards the students' own cultural group lead to proficiency. Their research to some extent supported the dichotomy of integrative/instrumental; however, they believed that these terms needed to be redefined based on personal traits of the community members. Gliksman, Gardner and Smythe (1982) tested students in grades 9, 10, and 11 at the beginning of the term and observed them in class once every two weeks for four months, and found that those students who were marked as integratively motivated, volunteered answers more frequently, gave more correct answers, and were rated as more interested in class than students who were not integratively motivated. These results were consistent for all assessments of classroom behavior.

Strong (1984) studied the relationship between integrative motivation and acquired second language proficiency among a group of Spanish-speaking kindergarteners in America. He found no positive relationship between integrative motivation and acquired English proficiency. A further comparison of beginners and advanced level English speakers showed the advanced learners had more integrative motivation towards the target language than the beginners.

Svanes (1987) investigated the acquisition of Norwegian language by foreign students from different cultures with regard to integrative and instrumental sort of motivation. The findings indicated that American and European learners were more integratively motivated than the Middle Eastern, African and Asian students while the latter group were more instrumentally motivated than their western peers.

Clement, Dornyei and Noels (1994) acknowledged the importance of integrative motivation in the classroom research. In their view in a setting where foreign language learning is largely an academic matter, students' motivation remains socially grounded. They do not regard instrumentality and integrativeness as two ends of an axis, which are antithetical; instead, they hold that they can correlate positively with each other. Van de Klein (1995)'s research did not support the suggestion of a relationship between integrative motivation and inclination to contact French people. Tamada (1996) carried out a study on 24 Japanese students who were learning English as a second language in the context of England and found that differences in motivation (instrumental versus integrative) significantly influenced the use of language learning strategies. Other studies done in this area are as follows: Ramazanian (1998); Hassanpur (1999); Chang and Huang (1999); Salimi (2000); Sedaghat (2001); Roohani (2001); Hassani (2005); Fazel and Razmjoo (2007); Neissi (2007); and Zarei (2009).

The present study is an attempt at finding the relationship between the type of motivation and language proficiency as determined through IELTS. The study is specifically after the following research questions:

1. Is there a relationship between instrumental motivation and writing proficiency among Iranian IELTS candidates?

2. Is there a relationship between integrative motivation and writing proficiency among IELTS candidates?

3. Is there any significant difference between the instrumentally motivated and integratively motivated candidates in their writing proficiency?

4. Is there a relationship between the writing proficiency of the instrumentally motivated candidates with their language proficiency?

5. Is there a relationship between the writing proficiency of the integratively motivated candidates with their language proficiency?

\section{METHOD OF THE STUDY}

\section{A. Participants}

The participants of the study were initially 245 Iranian IELTS candidates who had taken the actual IELTS test in Iran (academic module). All the participants sat for the actual IELTS test held in IELTS Center of International University of Chabahar in Tehran, on 26th May 2009. All participants, both males and females, were from Iran and spoke Farsi as their first language. To minimize the effect of age on the study, the range of 18 to 27 was chosen, as a result, 29 candidates whose ages were above or below the range were excluded from the study. The type of motivation each participant possessed was then determined. The participants of the study selected one of the five choices which were given for each item and their responses were scored on the basis of the Likert-scale. To avoid any confusion and enhance validity, the Persian version of the questionnaire was utilized. It went without saying that, items 9 to 12 and 13 to 16 were needed for the purpose of this study (Section 3.2.2). The choices were given numerical values from 5 to 1 that manifested the degree of the preference or tendency of the participants to the items of the questionnaire. The numerical value 5 was assigned to 'strongly agree', 4 to 'agree', 3 to 'undecided', 2 to 'disagree', and 1 to 'strongly disagree'. The scores for the items, then, are summed up and averaged. It was found that 86 candidates were integratively motivated, 110 instrumentally motivated and 20 stood in borderline. The twenty borderline candidates were left out and the remaining 196 candidates (110 instrumental candidates, and 86 integrative candidates) were selected for the purposes of the study. To make sure that the two groups did not differ in terms of their language proficiency, a one-way ANOVA was run on the scores of the students on the IELTS Test and no statistically significant difference was found. 
TABLE 1.

ONE-WAY ANOVA FOR PROFICIENCY SCORES

\begin{tabular}{|ll|l|l|l|l|l|}
\hline \multicolumn{2}{l}{} & Sum of Squares & df & Mean Square & F & Sig. \\
\hline IELTS & Between Groups & .561 & 1 & .561 & 3.860 & .051 \\
Proficiency & Within Groups & 28.187 & 194 & .145 & & \\
Scores & Total & 28.748 & 195 & & & \\
& N & & & & \\
\hline
\end{tabular}

As shown in Table 1, the computed significance is 0.051 , which is greater than the significance level set for the study (0.05). Statistically, it follows that there is not a significant difference between the two groups. Consequently, the groups are not different in terms of their proficiency scores; it means that the candidates in the two groups are statistically at the same level in terms of their proficiency performance.

\section{B. Instruments}

\section{IELTS Test}

The information presented in this and subsequent parts are mainly gathered from IELTS Handbooks, and the official website of IELTS (www.IELTS.org). IELTS, the International English Language Testing System, is designed to assess the language ability of candidates who need to study or work where English is the language of communication. IELTS conforms to the highest international standards of language assessment (UCLES, 2005). It covers the four language skills _ listening, reading, writing and speaking. One of the steps of the present study was to assess the subjects' level of proficiency. A further problem was that the subjects" "writing proficiency" ability was in the focus of the study. In other words, the job of the investigator was to identify the subjects' level of proficiency and their writing proficiency ability. Moreover, practical considerations (like the subjects' unwillingness to cooperate) made it even more urgent to hit the two goals with one shot. The justification for this choice lies in the "reliability and validity" claims for the IELTS made by the University of Cambridge Local Examinations Syndicate (UCLES). For further information, please refer to section 3.2.1.4.

\subsection{Reliability of IELTS}

IELTS differs from the Cambridge exams in that published reports recognize the need to address reliability and include information to that effect. For example, IELTS manuals describe a detailed approach to the certification of interviewers/assessors for the speaking test and raters for the writing component that requires re-certification procedures every two years. This process of training raters is commendable. IELTS developers report that the speech and writing samples are re-rated when there is an inconsistency in the profile of the scores and that centers are monitored as part of regular reliability studies conducted by the developers. Such information, while reassuring, needs to be augmented with research evidence.

It has always been important to maintain adequate reliability in both the objectively and the subjectively marked modules of IELTS. A rigorous process of test production has produced Reading and Listening versions with an average Cronbach Alpha of 00.88, calculated from the performance of over 90,000 candidates on thirteen reading and listening versions (UCLES, 2007). The reliability of Speaking and Writing Modules cannot be estimated in the same way, but quality is assured through a comprehensive program of training, certification, and monitoring of examiners. Performance in the Speaking Module is recorded onto cassette and the recorded interviews, together with scripts from the Writing Module, are kept by the test center for a minimum of two months. All IELTS results are routinely checked prior to release, and automatic remarking is required where consistent profile scores across the four skill areas are identified. In addition, a formal procedure now allows candidates to query their results within one month of the results being issued.

1.2. Reporting IELTS Composite Reliability

The IELTS exam contains four components upon which an overall band score is awarded. Thus an estimate of composite reliability offers a useful measure for overall test reliability. The method to estimating the reliability of a composite test used here is taken from Feldt \& Brennan (1989).

Composite reliability estimates were carried out from the period 1st January to 20 December, 2004. To generate an appropriately cautious estimate, minimum alpha values were used for the objectively marked papers; and g-coefficients for the single rater condition on subjectively marked scores. The composite reliability estimate for the Academic module was 0.95 and produced a composite SEM of 0.21 . This finding shows a $95 \%$ probability for a candidate's true score to fall within less than half a band $(0.41)$ of the observed score. For General Training the composite reliability was 0.95 with a SEM of 0.23 . In order to estimate how reliable the use of IELTS is, the reliability index for the IELTS was also found to be .83 with 541 Iranian learners through a pilot study by Salmani-Nodoushan (2002), which is considered a positive reliability.

\section{Validity of IELTS}

The phrase "international English language" in IELTS' name represents a distinguishing feature of this assessment as it acknowledges the ever-expanding status of English as an international language. Researchers such as Ingram and Wylie (1993) and Clapham (1996), however, indicate that IETLS' representation of the language construct is rooted in the skills and components models typically used in language testing. 
IELTS' manuals point out that the internationalization of the test refers to the partnership of the British Council and UCLES, on the one hand, and the International Development Projects (IDP) Education Australia, on the other. Additionally, IELTS' publications state: " the fact that test materials are generated in both the UK and Australia ensures that the content of each test reflects an international dimension" (IELTS, July 1996, p. 16). Research documenting claims that IELTS can be used as a measure of English as an international language needs to be made available.

IELTS' commitment to research and its responsiveness to research findings is well documented in the literature. In the late 1980s and early 1990s, IELTS underwent major changes - from a test with three academic subject modules to its current form. According to Clapham (1996), IELTS had intended the change to be more of a revision. Nevertheless, based on the results of various investigations, IELTS' developers made more comprehensive changes to the test. As such, IELTS has shown commitment to test practices informed by research findings. As argued above, due to the fact that the IELTS is a standard test of proficiency, its validity and reliability were assumed to be satisfactory.

\section{Motivation Questionnaire}

The second data collection instrument was the motivation questionnaire. It was used to collect data on the students' instrumental and integrative motivation. The motivation questionnaire designed by Laine (1987) and validated by Salimi (2000). The reliability of the questionnaire was further tested through test-retest method of estimating reliability by Fazel (2002). The reliability index for the questionnaire obtained through this method was 0.80 . To avoid any confusion and enhance validity, the Persian version of the questionnaire was utilized. The questionnaire is made up of 20 questions, questions 1 to 4 measure the students' direction of motivation, questions 5 to 8 attempt to measure the students' intensity (strength) of motivation, items 9 to 12 measure the students' instrumental motivation and questions 13 to 16 measure the students' integrative motivation and finally items 17 to 20 measure the students' cognitive motivation. The format of the questionnaire items was likert. The respondents were asked to indicate their motivation by choosing one of the five alternatives, strongly agree, agree, Undecided, Disagree, and Strongly disagree. The participants of the study selected one of the five choices which were given for each item. The choices were given numerical values from 5 to 1 that manifested the degree of the preference or tendency of the participants to the items of the questionnaire. The scores for the items are summed up and averaged to yield a questionnaire score and interpreted the differences between shades of opinion from ' strongly agree ' to 'strongly disagree'. Accordingly, the participants, based on their scores divided into instrumental and integrative motivation groups.

\section{Data Collection}

The required data were collected in two places in International Chabahar University and in IELTS Center of International University of Chabahar in Tehran. To gather the data, the motivation questionnaire was distributed among the candidates who took part in IELTS preparation course held in Chabahar International University. To avoid any confusion and enhance validity, the Persian version of the questionnaire was utilized. Fazel (2002) and Fazel \& Razmjoo, (2007) also used that Persian version in their study. Before administrating the questionnaire the researchers explained the nature of the questionnaire and the participants were requested to complete the questionnaires patiently and with utmost attention and asked them to provide identifying information such as name, level and age. Then, instructed the students to read each statement carefully, chose the appropriate responses and put a tick on the answer sheet. It went without saying that, items 9 to 12 and 13 to 16 were needed for the purpose of this study.

The candidates sat for the actual IELTS test held in IELTS Center of International University of Chabahar in Tehran, on 26th May 2009, and their IELTS scores (reported to/ made available to the investigator by Chabahar International University) are utilized as data obtained from language and writing proficiency tests necessary for this thesis.

\section{E. Data Analysis}

In order to investigate answers to the proposed questions, the results obtained from the IELTS and the motivation questionnaire were analyzed and the following statistical analyses were run on the data:

1. One-way ANOVA: One-way ANOVA was used to compare the mean scores for two different groups of instrumentally oriented students with those of their integratively oriented peers so as to realize whether the participants in the two groups differ in their proficiency or not.

2. Pearson Correlation Coefficient: Correlation analysis was used to describe the strength and direction of the linear relationship between the variables.

\section{RESULTS AND DISCUSSION}

\section{A. Descriptive Statistics}

Table 2 shows descriptive statistics for the scores of the subjects on the IELTS proficiency test. The table provides a summary of minimum, maximum and mean scores, as well as standard deviations in listening, reading, writing, speaking and overall IELTS scores. 
TABLE 2.

DESCRIPTIVE STATISTICS FOR THE SCORES OF THE SUBJECTS ON THE IELTS PROFICIENCY TEST.

\begin{tabular}{|c|c|c|c|c|c|c|}
\hline \multicolumn{2}{|c|}{ Group motivation } & $\mathrm{L}$ & $\mathrm{R}$ & $\mathrm{W}$ & $S$ & IELTS Proficiency Scores \\
\hline \multirow{4}{*}{$\begin{array}{l}\text { Integrative } \\
\text { motivation }\end{array}$} & Mean & 5.5767 & 6.5349 & 6.8140 & 6.1233 & 6.2622 \\
\hline & Std. Deviation & .79523 & .81454 & .71145 & .97228 & .40784 \\
\hline & Minimum & 3.00 & 5.00 & 5.50 & 4.50 & 5.12 \\
\hline & Maximum & 6.60 & 8.00 & 8.00 & 8.00 & 6.90 \\
\hline \multirow{4}{*}{$\begin{array}{l}\text { Instrumental } \\
\text { motivation }\end{array}$} & Mean & 6.5455 & 5.7600 & 6.6473 & 6.5273 & 6.3700 \\
\hline & Std. Deviation & .83651 & .92282 & 1.02998 & .87482 & .35901 \\
\hline & Minimum & 5.00 & 3.00 & 5.00 & 5.00 & 5.75 \\
\hline & Maximum & 8.50 & 8.50 & 8.50 & 8.50 & 7.25 \\
\hline \multirow[t]{4}{*}{ Total } & Mean & 6.1204 & 6.1000 & 6.7204 & 6.3500 & 6.3227 \\
\hline & Std. Deviation & .94819 & .95595 & .90582 & .93822 & .38396 \\
\hline & Minimum & 3.00 & 3.00 & 5.00 & 4.50 & 5.12 \\
\hline & Maximum & 8.50 & 8.50 & 8.50 & 8.50 & 7.25 \\
\hline
\end{tabular}

As the table demonstrates, minimum scores for the participants in integrative-group and instrumental-group are recorded as ' 5.12 ' and ' 5.75 ' respectively. The maximum scores are ' 6.90 ' for integrative-group and ' 7.25 ' for instrumental-group. The resulting data demonstrate more or less the same characteristics of the subjects in the two groups.

As can be understood from the table above, there is a slight difference between the mean scores of the two groups (' 6.26 ' and ' 6.37 ' for integrative-group and instrumental-group respectively). This can be an evidence of more or less the same level of proficiency of the participants in each group.

The standard deviation measures how widely spread the values in a data set are. Then the obtained results for integrative -candidates (0.40) and instrument-candidates (0.35) indicate how far from the mean the data points tend to be. Since the standard deviations are small, the data set are said to be close to the mean. The small standard deviation indicates more or less homogeneous groups.

In the table below (Table 3 ) the participants are characterized with respect to their motivation type and their scores on the proficiency test as well as theirs on the writing performance test.

TABLE 3.

PARTICIPANTS' MOTIVATION TYPES AND THEIR PROFICIENCY LEVELS

\begin{tabular}{|l|l|l|}
\hline Motivation & Instrumental & Integrative \\
\hline Number & 110 & 86 \\
\hline Proficiency Mean & 6.37 & 6.26 \\
\hline Proficiency SD & .35 & .40 \\
\hline Writing Perf. Mean & 6.64 & 6.81 \\
\hline Writing Perf. SD & 1.02 & .71 \\
\hline
\end{tabular}

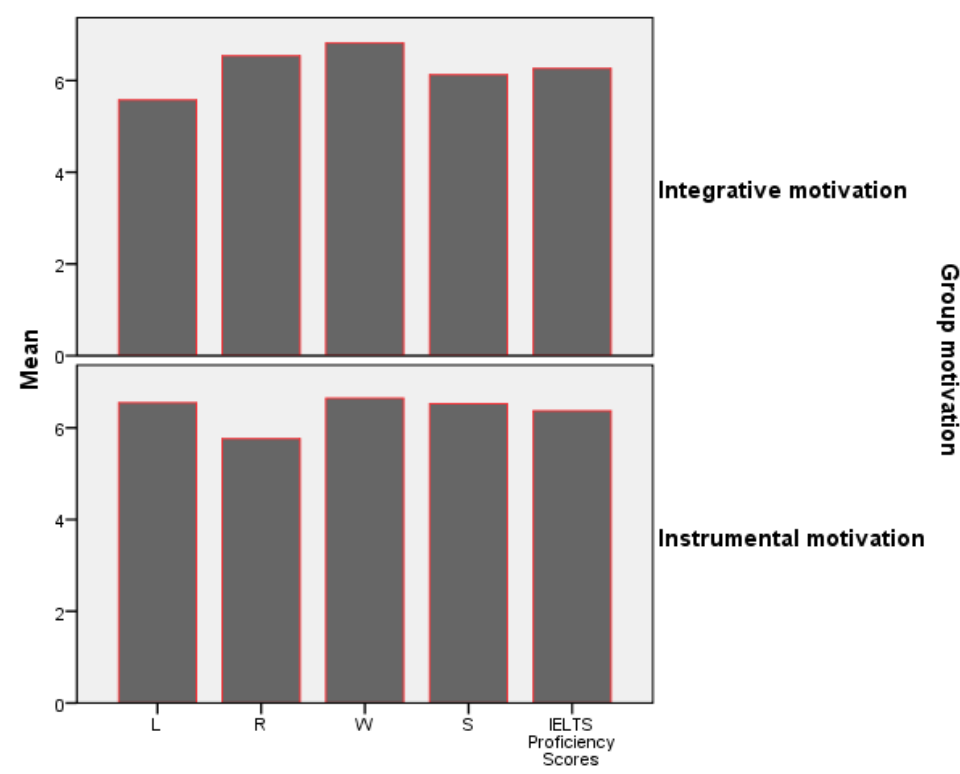

Figure 1. Bar graph based on the mean of participants in each motivation group 
As shown in Figure 1, the mean scores of the listening, reading, writing, speaking in each section and overall IELTS scores is shown as a bar graph. Here is not a significant difference between the two groups (Integrative motivation and Instrumental motivation). Consequently, the groups are not different in terms of their mean scores.

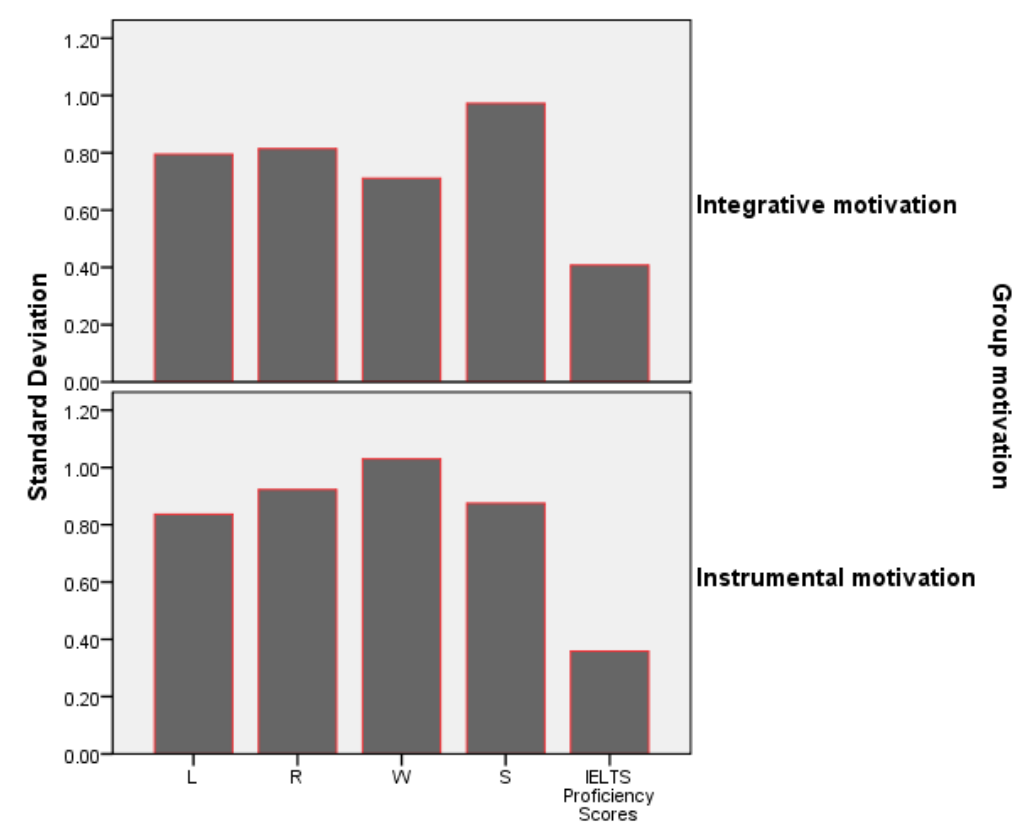

Figure 2. Bar graph based on the standard deviation of participants in each motivation group

As could be understood from the figure above, the standard deviation of the listening, reading, writing, speaking in each section and overall IELTS scores is indicated as a bar graph. There is not any significant difference between Integrative motivation and Instrumental motivation. Therefore, the groups are not different in terms of their standard deviation.

\section{B. Inferential Statistics}

Inferential statistics deals with appropriate data analysis to answer the research questions of the study. In order to provide answers to the posed questions of the present study, the researchers have taken the following data analysis into consideration.

1. Is there a relationship between instrumental motivation and writing proficiency among Iranian IELTS candidates?

To find out whether there was any significant relationship between candidates' instrumental motivation towards their IELTS writing scores, Pearson Product Moment Correlation was run between candidates' instrumental motivation scores and their TELTS writing scores. The results are summarized in Table 4.

TABLE 4.

PEARSON CORRELATION COEFFICIENT BETWEEN INSTRUMENTAL MOTIVATION AND WRITING PROFICIENCY

\begin{tabular}{|c|c|c|}
\hline & & Writing Proficiency Scores \\
\hline \multirow[t]{3}{*}{ Instrumental motivation } & Pearson Correlation & $.298^{* *}$ \\
\hline & Sig. (2-tailed) & .002 \\
\hline & $\mathrm{N}$ & 110 \\
\hline
\end{tabular}

Correlation is significant at the .01 level (2-tailed)**

As shown in Table 4, the correlation is '.298' and p-value is '.002'. Thus, it can be concluded that there is a correlation between instrumental motivation and writing proficiency. The size of value of correlation usually can range from ' -1.00 ' to ' 1.00 '. This value will indicate the strength of the relationship between language proficiency and the use of each subcategory. A correlation of 0 indicates no relationship, a correlation of ' 1.0 ' indicates a perfect positive correlation and a value of ' -1.0 ' indicates a perfect negative correlation (Pallant, 2005).

2. Is there a relationship between integrative motivation and writing proficiency among IELTS candidates?

To find out whether there was any significant relationship between candidates' integrative motivation towards their IELTS writing scores, Pearson Product Moment Correlation was run between candidates' instrumental motivation scores and their TELTS writing scores. The results are summarized in Table 5. 
TABLE 5.

PEARSON CORRELATION COEFFICIENT BETWEEN INTEGRATIVE MOTIVATION AND WRITING PROFICIENCY

\begin{tabular}{|c|c|c|}
\hline & & Writing Proficiency Scores \\
\hline \multirow[t]{3}{*}{ Integrative motivation } & Pearson Correlation & $.329^{* *}$ \\
\hline & Sig. (2-tailed) & .002 \\
\hline & $\mathrm{N}$ & 86 \\
\hline
\end{tabular}

Correlation is significant at the .01 level (2-tailed)**

As shown in Table 5, a significant relationship was found at 0.01 level of significance $(\mathrm{P}=.002)$. Thus, it can be concluded that there is a correlation between integrative motivation and writing proficiency.

3. Is there any significant difference between the instrumentally motivated and integratively motivated candidates in their writing proficiency?

In order for the study to find out which group (instrumental or integrative) of the candidates was better in terms of their writing performance, one-way Analysis Of Variance (ANOVA) was made use of. One-way ANOVA demonstrates the significant differences in the mean scores on the dependent variable (Pallant, 2005). In Table 6, the means of instrumental and integrative groups are compared, based on the mean of the scores obtained from the writing scores so as to determine which group (integrative or instrumental) scored higher on each test.

TABLE 6.

ONE-WAY ANOVA FOR INSTRUMENTAL AND INTEGRATIVE GROUPS IN TERMS OF THEIR WRITING PERFORMANCE

\begin{tabular}{|lc|l|l|l|l|l|}
\hline & & Sum of Squares & df & Mean Square & F & Sig. \\
\hline Writing & Proficiency & Between Groups & 1.341 & 1 & 1.341 & 1.640 \\
Scores & Within Groups & 158.657 & 194 & .818 & .202 \\
& Total & 159.998 & 195 & & & \\
\hline
\end{tabular}

As shown in Table 6, the existing significance value (.202) is larger than the significance level (p>0.05). In other words, there are no significant differences between the two groups of learners (instrumental vs. integrative groups) in terms of their writing performance.

The fourth research question:

4. Is there a relationship between the writing proficiency of the instrumentally motivated candidates with their language proficiency?

Table 7 provides the actual value of the Pearson Correlation Coefficient between the variables along with the $\mathrm{p}$-value.

TABLE 7.

PEARSON CORRELATION COEFFICIENT BETWEEN WRITING PROFICIENCY OF THE INSTRUMENTALLY MOTIVATED CANDIDATES WITH THEIR LANGUAGE PROFICIENCY

\begin{tabular}{|ll|l|}
\hline & \multicolumn{2}{|c|}{ PROFICIENCY } \\
\hline Writing Proficiency Scores & Pearson Correlation & $.415^{* *}$ \\
& Sig. (2-tailed) & .000 \\
$\mathrm{~N}$ & 110 \\
\hline
\end{tabular}

As the Table 7 shows, the correlation is ' .415 ' and p-value is '.000'. Thus, it can be concluded that the correlation coefficient is significant. On the other words, there is a significant correlation between writing proficiency of the instrumentally motivated candidates with their language proficiency.

5. Is there a relationship between the writing proficiency of the integratively motivated candidates with their language proficiency?

Table 8 gives the actual value of the Pearson Correlation Coefficient along with the p-value demonstrating the existing relationship between writing proficiency of the integratively motivated candidates with their language proficiency

TABLE 8.

PEARSON CORRELATION COEFFICIENT BETWEEN WRITING PROFICIENCY OF THE INTEGRATIVELY MOTIVATED CANDIDATES WITH THEIR LANGUAGE PROFICIENCY

\begin{tabular}{|ll|l|}
\hline & & IELTS Proficiency Scores \\
\hline Writing Proficiency Scores & Pearson Correlation & $.248^{*}$ \\
& Sig. (2-tailed) & .021 \\
$\mathrm{~N}$ & 86 \\
\hline
\end{tabular}


As could be inferred from the table, the direction of the relationship between the existing variables is positive. It implies, the correlation is ' .248 ' and the p-value is '. 021 '.. It means that there is a linear correlation between the writing proficiency of the integratively motivated candidates with their language proficiency.

\section{CONCLUSION}

Motivation is probably the most frequently used catch-all term for explaining the success or failure of virtually any complex task. It is easy to assume that success in any task is due simply to the fact that someone is"motivated". There are many contributing factors in order for any kind of learning to take place. One of the determining factors recognized to be involved in learning is motivation.

On the other hand, writing as one of the four language skills, and most often as the last one, plays an important role in the processes of language learning. Chastain (1988) states that writing skill is viewed as a basic communication skill and a unique asset in the process of learning a second language. Writing is considered as a wing of literacy and plays a very important role in today's world. As a case in point, much of the information exchange around the world takes place through written texts. Besides, the rapid development in every field is due to the ability of the researchers to write their findings and actually record them. Nowadays writing is thought of as a skill in whose teaching all language skills are involved. In other words, it is a whole-language teaching skill since its teaching involves practicing all language skills (i.e., speaking, reading, listening, and writing). Writing proficiency seems to be necessary in both academic environments (e.g., writing papers, theses, etc.) and non-academic situations (e.g., writing letters, invitation, etc.). Finally, it increases language retention as well as ensuring availability for later use and reference. It seems, thus, that teaching and learning this skill can be the most demanding task for both teachers and students. This means that writing requires a good command of language knowledge as well as the orchestration of several processes. Therefore, it may be reasonable to survey different views concerning this skill as well as the methods writing has been taught in different periods of time.

Globally, language learners attempt to attain certain goals, one of the most significant of which is writing achievement. Throughout the history of education, language researchers have been at pains to find effective ways to help students achieve writing as a major skill. It goes without saying that motivation has a leading role in gaining writing proficiency. The point at issue is what type of motivation can be more conducive to writing achievement.

Finding ways around to enhance writing as a major skill has always been of great interest to educators in the field of language teaching. Numerous studies have been conducted on the influence of motivation and motivational factors; nonetheless, as yet there has not been a comprehensive study on the study of relationship between integrative and instumental motivation of students and their relationship with writnig proficiency among Iranian IELTS candidates. To this end, this study investigates the role motivation plays in improving writing and gaining writing proficiency, the results of which can serve to help the board of education at universities as well as institutes nationwide to take measures so as to instill stronger motivation among the students and consequently deal with the existing problems which students across the country experience in writing.

In addition to the afore-mentioned objective, the classification of motivation into integrative and instrumental by Gardner and Lambert (1972) and the effect each can have on writing as well as on proficiency is studied for the first time ever in an Iranian context, the results and implications of which can serve to give teachers an in-depth understanding of motivation as one of the factors which can optimize learning.

This finding accords with Gardner and Lambert (1972) who carried out empirical studies in different contexts showing the effect of two different types of integrative and instrumental motivation on $\mathrm{L}_{2}$ learning. Results in Quebec and Ontario indicated that the kind of motivation and attitude towards speakers of the target language $\left(\mathrm{L}_{2}\right)$ played a key part in the process of $\mathrm{L}_{2}$ acquisition. Students with integrative orientation were found to be more successful as compared with those with instrumental motivation.

The findings of the study also stand in contrast with Strong (1984) who studied the relationship between integrative motivation and acquired second language proficiency among a group of Spanish-speaking kindergarteners in America. He found no positive relationship between integrative motivation and acquired English proficiency.

To wrap up, Findings of the current study indicated that there is a significant relationship between both instrumental and interagative motivation and writing proficiency among Iranian IELTS candidates. However, There is no significant difference between the instrumentally motivated and integratively motivated candidates in their writing proficiency. On the other hand, There is a significant relationship between the writing proficiency of the instrumentally and integratively motivated candidates with their language proficiency.

\section{REFERENCES}

[1] Brown. H.D. (1987). Principles of language learning and teaching ( $2^{\text {nd }}$ ed.). Englewood Cliffs, NJ: Prentice Hall.

[2] Brown. H.D. (2007). Principles of language learning and teaching ( $5^{\text {th }}$ ed.). Addison Wesley, New York: Longman.

[3] Chang, S. F., and Huang, S. C. (1999). Language Learning Motivation and Language Strategies of Taiwanese EFL Students. Eric N.O. : ED 371589.

[4] Chastain, K. (1988). Developing second language skills: theory and practice $\left(3^{\text {rd }}\right.$ ed). New York: Harcourt Brace and Jovanovich. 
[5] Chomsky, N. (1988). Language and Problems of Knowledge. Cambridge Mass: MLT Press.

[6] Clapham, C. (1996). The Development of IELTS: A Study of the Effect of Background Knowledge on Reading Comprehension. Cambridge University Press, Cambridge.

[7] Clement, R., Dornyei Z., \& Noels, K. A. (1994). Motivation, self-confidence and group cohesion in foreign language classroom. Language Learning, 44(3), 419-448.

[8] Deci, E. L., \& Ryan, R. M. (1985). Intrinsic motivation and self-determination in human behavior. New York: Plenum Press.

[9] Falk, J. (1978). Linguistics and language: A survey of basic concepts and implications (2 ${ }^{\text {nd }}$ ed.). New York: John Wiley and sons.

[10] Fazel, I. (2002). Effects of Motivation on Oral Proficiency Among Iranian Female Students Of English At Shiraz University Language Center. Unpublished M.A. Thesis. Shiraz University, Shiraz, Iran.

[11] Fazel, I. \& Razmjoo, S. A. (2007). The Impact of Motivation Types (Instrumental Versus Integrative) Upon Speaking Ability. Pan-Pacific Association of Applied Linguistics. 11(1), 49-67.

[12] Feldt L.S \& Brennan R. L. (1989). Reliability. In Linn (Ed): Educational Measurement, 3rd Edition. American Council on Education: Macmillan.

[13] Gardner, R.C. (1968) Attitudes and motivation: Their role in second language acquisition. TESOL, Vol. 2, 141-149.

[14] Gardner, R.C. (1979). Social-psychological aspects of second language acquisition. In H. Giles and R.S. Clair (Eds.), Language and social psychology, pp. 193-220. Oxford: Basil Blackwell.

[15] Gardner, R. C. (1985). Social psychology and second language learning: The role of attitude and motivation. London: Edward Arnold.

[16] Gardner, R.C., \& Lambert, W.E. (1959). Motivational variables in second language acquisition. Canadian Journal of Psychology, Vol. 13, 266-272.

[17] Gardner, R.C., \& Lambert, W. E. (1972). Attitudes and motivations in second language learning. Rowley: Newbury House Publishers.

[18] Gliksman, L., Gardner, R. C., \& Smythe, P. C. (1982). The role of the integrative motive on students' participation in the French classroom. Canadian Modern Language Review, 38, 625-647.

[19] Hassani, H. (2005). The relationship between intrinsic and extrinsic motivation and Iranian EFL Students' gender, Level of University Instruction, and the EFL proficiency. Unpublished M.A. thesis. Shiraz University, Shiraz, Iran.

[20] Hassanpur, M. (1999). Science Students Use of Language Learning Strategies and its Relation to Motivation, Attitude and Gender. Unpublished M.A. Thesis. Shiraz Islamic Azad University. Shiraz.

[21] Hudson, G. (2000). Essential introductory linguistics. Boston: Blackwell Publishers.

[22] IELTS (International English Language Testing System). (1996). IELTS Annual Report: 1995. UCLES, The British Council, and IDP Education Australia, Cambridge.

[23] Ingram, D.E., Wylie, E. (1993). Assessing speaking proficiency in the international English language testing system. In: Douglas, D., Chapelle, C. (Eds.), A New Decade of Language Testing Research. TESOL, Alexandria, VA, pp. 220-234.

[24] Keller, J. M. (1983). Motivation: Design of Instruction. In C.M. Reigeluth (Ed.), Instructional design theories and models (pp. 386-433). Hillsadale, NJ: Erlbaum.

[25] Laine, J. E. (1987). Affective Factors in Foreign Language Learning and Teaching Cross-Language Studies, (No 13). Jyvaskyla: Jyvaskyla University, Department of English.

[26] Lukmani, Y. M. (1972). Motivation to learn and language proficiency. Language Learning, 22(2), 261-273.

[27] Neissi, S. (2007). Relationship Between Self-Esteem, Achievement Motivation, Academic Performance of EFL Learners. Unpublished M.A. Thesis. Shiraz University, Shiraz, Iran.

[28] Noels, K. (2001). New orientations in language learning motivation. In Z. Do“rnyei \& R. Schmidt

[29] Oller, J. W., Baca, L., \& Vigil, F. (1977). Attitudes and attained proficiency in ESL: A sociolinguistic study of Mexican Americans in the Southwest. TESOL Quarterly, 11, 175-183.

[30] Oller, J. W., \& Perkins, K. (1978). Intelligence and language proficiency as a source of variance in self-reported affective variables. Language Learning, 28(1), 85-97.

[31] Oxford, R., \& Shearin, J. (1994). Language learning motivation: Expanding the theoretical framework. Modern Language Journal, 78(1), 11-28.

[32] Ramazanian, M. (1998). The motivation for language learning among Shiraz University undergraduate students of English as a foreign language. Unpublished M.A. thesis. Shiraz University, Shiraz, Iran.

[33] Pallant, J. (2005). SPSS Survival Manual: A Step by Step Guide to Data Analysis Using SPSS for Windows. Buckingham: Open University Press.

[34] Roohani, A. (2001). An Investigation Into EFL Students' Motivation in Shiraz State and Islamic Azad University. Unpublished M.A. thesis. Shiraz University, Shiraz, Iran.

[35] Salimi, M. R. (2000). Affective Factors in Learning English: A Study of the Filter. Unpublished M.A. Thesis. Shiraz University, Shiraz, Iran.

[36] Salmani-Nodoushan, M. A. (2002). Text Familiarity, Reading Task, and ESP Text Performance: A Study on Iranian LEP AND NON-LEP University Students. Unpublished Ph.D. Dissertation, University of Tehran, Tehran.

[37] Sato, K. (2005). Does instruction help learners become proficient in $\mathrm{L}_{2}$ writing? The case of the Japanese particles wa, ga, and the passive. Dissertation Abstracts International, 66(7), 2560.

[38] Sedaghat, M. (2001). The Effects of Attitude, Motivation and Proficiency Level On the Use of Listening Comprehension Strategies by Iranian Female Learners. Unpublished M.A. Thesis, Shiraz University. Shiraz,Iran.

[39] Strong, M. (1984). Integrative motivation: Cause or result of second language acquisition? Language Learning, 34, 1-14.

[40] Svanes, B. (1987). Motivation and cultural distance in second language acquisition. Language Learning, 37(3), $341-358$.

[41] Tamada, y. (1996). The relationship between Japanese Learners, personal factors and their choices of language learning strategies. Modern Language Journal, 80(12) , 120-131. 
[42] UCLES. (2005). IELTS handbook 2005. Retrieved from the IELTS Web site: http://www.ielts.org/pdf/IELTS_Handbook_2005.pdf

[43] UCLES. (2007). IELTS handbook 2007. Retrieved from the IELTS Web site: http://www.ielts.org/pdf/IELTS_Handbook_2007.pdf

[44] Van der Klein, M. (1995). Use of French, attitudes and motivations of French immersion students. The Canadian Modern Language Review, 51(2), 287-301.

[45] Zarei, L. (2009). The Relationship Between Iranian EFL Learners, Foreign Language Classroom Anxiety, Intrinsic/Extrinsic Motivation \& Course Achievement. Unpublished M.A. Thesis. Shiraz University, Shiraz, Iran.

Ismaeil Fazel earned his Master's degree in teaching English as a foreign language from Shiraz University in Iran in 2003.

$\mathrm{He}$ has been teaching English at institutional and academic levels for the past 10 years. He served as a member of faculty at Hormozgan University of Medical Sciences for 5.5 years. He has been teaching at Vancouver Georgia College since October 2010. Some of his recent publications include: "Medical students' perceptions of the educational environment at an Iranian Medical Sciences University" (BMC Medical Education, 2010) and "Effects of Etymological Elaboration on the EFL Learners' Comprehension and Retention of Idioms" (Pan-Pacific Association of Applied Linguistics, 2010) and "Pseudo versus Genuine Eclecticism" (Roshd Foreign Language Teaching Journal, 2010).

Ismaeil Fazel is a member of International Association of World Englishes, and Canadian Association of Applied Linguistics.

Alireza Ahmadi received his Ph.D. in TEFL from the University of Isfahan in 2008, his MA in TEFL from Shiraz University in 2002 and his BA in English Translation from the University of Allameh Tabatabaei in 2000.

Currently, he is an assistant professor in the Department of Foreign Languages and Linguistics at Shiraz University, Iran. His main interests include Language Assessment and Second Language Acquisition. 